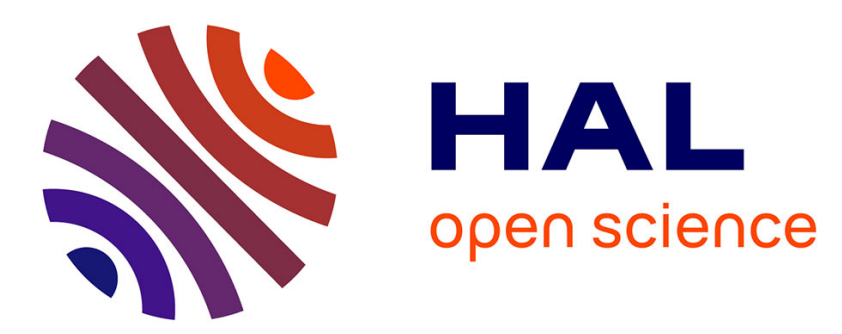

\title{
Earthworm excreta attract soil springtails: laboratory experiments on Heteromurus nitidus (Collembola: Entomobryidae)
}

Sandrine Salmon, Jean-François Ponge

\section{- To cite this version:}

Sandrine Salmon, Jean-François Ponge. Earthworm excreta attract soil springtails: laboratory experiments on Heteromurus nitidus (Collembola: Entomobryidae). Soil Biology and Biochemistry, 2001, 33 (14), pp.1959-1969. 10.1016/S0038-0717(01)00129-8 . hal-00501867

\section{HAL Id: hal-00501867 \\ https://hal.science/hal-00501867}

Submitted on 20 Aug 2010

HAL is a multi-disciplinary open access archive for the deposit and dissemination of scientific research documents, whether they are published or not. The documents may come from teaching and research institutions in France or abroad, or from public or private research centers.
L'archive ouverte pluridisciplinaire HAL, est destinée au dépôt et à la diffusion de documents scientifiques de niveau recherche, publiés ou non, émanant des établissements d'enseignement et de recherche français ou étrangers, des laboratoires publics ou privés. 


\title{
Earthworm excreta attract soil springtails: laboratory experiments on Heteromurus Nitidus (Collembola: Entomobryidae)
}

\author{
Sandrine Salmon*, Jean-François Ponge \\ Museum National d'Histoire Naturelle, Laboratoire d'Écologie Générale, 4, Avenue du Petit-Château, 91800 \\ Brunoy, France
}

\begin{abstract}
Microarthropods are often found more abundantly in soils with earthworms than in soils without. Earthworms probably create a favourable environment for microarthropods but few studies have aimed to explain this earthworm effect. The soil collembolan (Hexapoda) Heteromurus nitidus, living in soils at $\mathrm{pH}>5$ only and thus rich in earthworms, is particularly attracted by earthworms in humus cores. The effect of earthworms on the distribution of $H$. nitidus can be mediated either by direct contact or by odour perception. Two experimental designs were used to determine the pathway of attraction. The first set of experiments studied the effect of direct contact with earthworm excreta on the distribution of H. nitidus. The mixture of urine and mucus of the lumbricid earthworms Aporrectodea giardi and Alollobophora chlorotica signifcantly attracted $H$. nitidus as compared to deionized water while fresh earthworm casts were not preferred to calcic mull made of older casts. The same experiment involving direct contact with mucus and methyl blue showed that Collembola sucked on mucus/urine, indicating that the interaction of Collembola and earthworms was at least partly trophic. The second experiment demonstrated that H. nitidus was attracted by the odour of Aporrectodea giardi at short distance. The odour of excreta (mucus, urine and casts) of Aporrectodea giardi also attracted H. nitidus but this attraction was weaker and did not occur constantly, possibly due to interactions with light and aggregation pheromones. We conclude that the prominent pathway by which earthworms could attract $H$. nitidus in the field is through direct contact with earthworm mucus and urine. The acid-intolerant distribution of this species in the field could be partly explained by a trophic interaction with some earthworm species.
\end{abstract}

\footnotetext{
${ }^{*}$ Corresponding author. Tel.: +33-1-604-79241; fax: +33-1-60-46-50-09. E-mail address: ssalmon@ @mnn.fr (S. Salmon).
} 
Keywords: Attraction; Collembola; Lumbricidae; Mucus; Olfactory signal

\section{Introduction}

Collembolan communities vary in soils according to several factors, among them the presence of earthworms, high populations of which characterize mull humus forms with a moderately low to high $\mathrm{pH}$ (Satchell, 1967; Piearce, 1972). In fact, some studies have shown that the density and diversity of microarthropods increase in soils with earthworms (Bayoumi, 1978; Marinissen and Bok, 1988; Hamilton and Sillman, 1989; Loranger et al., 1998). Moreover, numerous Collembola have been observed directly wandering on giant earthworm bodies (Bouché personal communication) and in rearing beds of earthworms (Greenslade and Fletcher, 1986; Arbea and Jordana, 1988). However no attempt has been made to study direct positive effects of earthworms on the surrounding fauna.

Earthworms, through their action on the surrounding soil, improve water availability, aeration, and pore size (Wickenbrock and Heisler, 1997; Devliegher and Verstraete, 1997; Subler and Kirsch, 1998), which may attract microarthropods. In addition, earthworms increase the availability of a number of inorganic (Jeanson, 1972; Scheu, 1987; Robinson et al., 1992) and organic compounds (Dubash and Ganti, 1964; Martin et al., 1987), favour some bacteria (Kozlovskaja, 1969; Saetre, 1998) and increase or decrease fungal populations (Brown, 1995) on which Collembola may feed. These products may attract Collembola or favour their abundance and diversity.

The collembolan species Heteromurus nitidus is always found in soils at $\mathrm{pH}>5$ that generally bear mull humus (Ponge, 1993; Salmon and Ponge, 1999). This species seems to be particularly dependent on the presence of earthworms since mull humus is characterised by a high abundance of earthworms and particularly we demonstrated, from laboratory experiments, that Heteromurus nitidus preferred humus blocks with rather than without earthworms (Salmon and Ponge, 1999). However, we know neither the causes nor the pathway of this attraction. One or many of the substances and microorganisms excreted by earthworms (see above) may attract Collembola. In fact, fungal-feeding Collembola were able to discriminate between different fungal species and showed preferences among them (Shaw, 1988; Thimm and Larink, 1995; Kaneko et al., 1995). They recognized fungal odours and were attracted or repelled by them (Bengtsson et al., 1988; Hedlund et al., 1995; 
Sadaka-Laulan et al., 1999). Some Collembola were also attracted by a mite species (Huber, 1979). In addition, earthworms are known to attract other invertebrate species (Halpern et al., 1984; Morris and Pivnick, 1991).

The aim of this study was to determine the causes and the pathway of attraction of the collembolan $H$. nitidus by two earthworm species. Is $H$. nitidus attracted at a distance by the odour of earthworms or does it remain in the vicinity of the earthworms after direct contact? Earthworms and their excreta (mucus, urine and casts) were tested in odour experiments. In direct contact experiments, the effects of mucus plus urine, and casts, were studied. One experiment using earthworm mucus and urine and methyl blue was performed to assess whether mucus was consumed by Collembola. The present paper focuses on two lumbricid species Aporrectodea giardi and Allolobophora chlorotica which attracted H. nitidus in humus blocks (Salmon and Ponge, 1999). They were extracted from a calcic mull, a humus form in which H. nitidus is commonly found. The mechanisms of attraction and the impact of earthworms on the distribution of $H$. nitidus are discussed.

\section{Materials and methods}

\subsection{Test organisms}

Specimens of $H$. nitidus were reared in laboratory cultures on moist Fontainebleau sand (pure fine quartz sand). They were fed with lichens and terrestrial microalgae (Pleurococcus) from bark scrapings. Cultures were kept at $15^{\circ} \mathrm{C}$ in permanent darkness. Each experimental run was performed with new specimens.

Two earthworm species were sampled from a calcic mull in the laboratory park. Aporrectodea giardi is a large earthworm (150 mm in length) belonging to the anecic category (Bouché, 1972). Allolobophora chlorotica is smaller $(50 \mathrm{~mm})$ and classified as endogeic. The extraction was performed with $4 \%$ formalin a few days before the start of each experiment, and in the mean time earthworms were kept in their original soil at $15^{\circ} \mathrm{C}$ in darkness.

\subsection{Direct contact experiments}

\subsubsection{General protocol}


Direct contact experiments were performed in six Petri dishes $(\varnothing 8 \mathrm{~cm})$ containing two half-disks $(\varnothing 5$ $\mathrm{cm}$ ) of filter paper placed at $1.5 \mathrm{~cm}$ distance from each other. The dishes were placed on a laboratory table. Only one of the half-disks contained earthworm excreta (casts or mucus plus urine; see below), the other served as reference (calcic mull aggregates or water). Ten adult $H$. nitidus were taken randomly from the rearing boxes then introduced in each of the six Petri dishes (replicates), half-way between the two half-disks. Their abundance was counted on each half-disk every $10 \mathrm{~min}$ for $140 \mathrm{~min}$. Animals outside the half-disk areas were ignored. All runs were established at ambient temperature (around $20^{\circ} \mathrm{C}$ ), under homogeneous light conditions (checked with LI 1000 Data Logger and LI-COR Radiation sensors). The two half-disks were equally moistened. A control experiment was performed with both half-disks moistened with deionized water only, in order to verify that some factor other than earthworm excreta, especially light, did not influence the distribution of $H$. nitidus. This species is highly sensitive to light (Salmon and Ponge, 1998) and although light conditions were as homogenous as possible a control experiment was necessary to verify this point.

For each replicate, means of 14 time-measures of numbers of Collembola on each half-disks were calculated. The normality of the data was checked, and means of six replicates in 'earthworm excreta' were compared to means in 'reference substrate' by a paired t-test (Sokal and Rohlf, 1995).

\subsubsection{Experiments with mucus and urine}

Adult earthworms, eight A. giardi or 54 A. chlorotica, were rinsed under tap water. They were then placed on moistened filter paper to void their guts and kept at $15^{\circ} \mathrm{C}$ in darkness, in a water-tight plastic box, for $60 \mathrm{~h}$. The filter paper was renewed every $20 \mathrm{~h}$.

Three days after washing the worms, six half-disks of filter paper were saturated with mucus and urine by incubating them with the earthworms. For this purpose, half-disks and earthworms, the two species separately, were placed for $5 \mathrm{~h}$ in a water-tight enclosure at ambient temperature, in darkness. Mucus and urine were tested together because both are excreted from the wall of earthworms (Bouché, 1972). Six other half-disks were saturated with deionized water. H. nitidus could then choose between mucus plus urine or deionized water during $140 \mathrm{~min}$ as described above. As H. nitidus is known to be especially sensitive to desiccation (Bauer and Christian, 1987), the two half-disks were equally moistened (saturated) with deionized water or mucus plus 
urine.

\subsubsection{Experiments with casts}

$20 \mathrm{~h}$ before the start of the experiment eight adult A. giardi or 60 adult A. chlorotica were rinsed under tap water and added to Petri dishes $(014 \mathrm{~cm})$ containing moistened filter paper, to collect fresh casts. In order to condition reference substrates in the same manner, moistened filter paper lining the bottom of Petri dishes ( 014 $\mathrm{cm}$ ) was covered by calcic mull aggregates collected at the same time as earthworms. Earthworms and calcic mull were then kept at $15^{\circ} \mathrm{C}$ in darkness, in a water-tight enclosure. On the day of the experiment, fresh casts and calcic mull aggregates were smeared separately on six half disks each by means of a scalpel. Both types of half disk were deposited in each Petri dish (replicate). Thereafter, choice experiments were run as described above. H. nitidus could then choose between casts and calcic mull material with similar colour and consistency, the hemorganic horizon of calcic mull being formed of aged earthworm casts.

\subsubsection{Experiments with methyl blue}

A similar experiment with mucus plus urine of eight $A$. giardi was carried out on half-disks previously stained with methyl blue dye. Methyl blue was used to see whether Collembola grazed and absorbed the mucus/urine secretion. In each box the two half-disks were equally stained to prevent any differential effect of colour upon the distribution of Collembola. Twelve half-disks were impregnated by a methyl blue water solution $\left(25 \mathrm{~g} \mathrm{l}^{-1}\right)$ and left to dry in darkness for 6 days until the choice experiments started. During the experiment $H$. nitidus could choose between two blue half-disks, the one impregnated with mucus plus urine, the other with deionized water.

A control experiment was performed in which each test box contained two blue half-disks saturated with deionized water. This control experiment allowed verification of the harmlessness of the dye and a contrast between the absorptive behaviour of $H$. nitidus in the presence of water only and water and mucus plus urine (test-experiment). 
At the end of these choice experiments Collembola were transferred to ethanol (90\%) and the colour of their gut contents was observed under a dissecting microscope.

\subsection{Odour attraction experiments}

To test the attraction by the odour of earthworm excreta, 22 adult $A$. giardi were rinsed in tap water and then placed in three Petri dishes $(\varnothing 8 \mathrm{~cm})$ containing three or four disks of filter paper 1 day before the experiments started. Petri dishes with earthworms were then placed in a watertight plastic box in darkness at ambient temperature, for $20 \mathrm{~h}$, in order to impregnate the filter paper disks with earthworm excreta, i.e. mucus, urine and fresh casts. In the experiment where the odour of the earthworm itself (not its excreta) was studied, ten A. giardi were rinsed and used directly.

The experimental design allowed volatile compounds from earthworm excreta to diffuse without any contact or visual perception by Collembola (Fig. 1). All odour experiments comprised ten replicates ( = ten experimental chambers). The experimental chambers consisted of rectangular plastic boxes 11.4 X 8.4 X $6.5 \mathrm{~cm}$ ( $1 \mathrm{X} 1 \mathrm{X} \mathrm{h}$ ) divided into two compartments, each containing a plastic vessel filled with remoistened Fontainebleau sand. The top of one of the vessels was covered by a filter disk impregnated with A. giardi excreta. The other vessel was covered by a filter disk impregnated with deionized water only to obtain a similar moisture. The vessels were covered by a platform on which $12 \mathrm{H}$. nitidus individuals were allowed to wander. The platform varied according to the type of experiment (see below). Odour attraction experiments were accompanied by a control experiment, using the same apparatus but without earthworm excreta. This control experiment was designed to assess possible effects of other factors such as light on collembolan distribution.

In the first two sets of experiments, the platform for H. nitidus consisted of a moistened sheet of filter paper which was fixed to the box walls, $0.8-1 \mathrm{~cm}$ above the vessels (Fig. 1). The platform area was arbitrarily divided into two sectors by a drawn line. Above each vessel, the moist filter paper was perforated to allow the passage of lipophilic olfactory compounds through the suspended platform. Twelve adult or sub-adult $H$. nitidus (different for each replicate) were released over the suspended platform (six in each sector) and each test box was placed immediately in a dark enclosure. Light was present only during the short time spent for releasing (3 $\min )$ and counting (1 min) animals. 
In the first series of experiments $H$. nitidus individuals were counted in both sectors every $10 \mathrm{~min}$ for $2.5 \mathrm{~h}$. One experimental set assessed the effect of the odour of earthworm excreta, the other was a control experiment (two sectors 'no odour'). The second series of experiments, also comprising an odour and a control experimental set, was performed in the same device but Collembola were counted every 30 min over $7 \mathrm{~h}$ in order to have an overview of longer-term effects. Results were analysed as for direct contact experiments using paired t-test.

In the third series of experiments the apparatus was modified to allow for a better balance in the distribution of animals between the two sectors in the absence of an earthworm effect. Since the dispersal of Collembola is favoured by an increase in population density (Bengtsson et al., 1994), we reduced the size of the moist area by replacing the platform made of a filter paper sheet by two much smaller wet areas. The platform was made of a plastic sheet with two holes $(\varnothing 3.2 \mathrm{~cm})$ each covered with a perforated filter paper disk. Paper disks were moistened with an equal volume of deionized water to avoid the influence of varying humidity (Joosse and Verhoef, 1974). Twelve Collembola were released in the space between the two moist areas. Their number was counted on both filter paper disks each 30 min over $5.5 \mathrm{~h}$. A control experiment (a) with two areas 'no odour', was performed to verify the homogeneity of the distribution in the two areas in the absence of an earthworm effect. An experiment (b) was carried out to assess the odour of earthworm excreta as in the previous device. A third experiment (c) was performed after replacing earthworm excreta by the earthworm itself: an individual of $A$. giardi was introduced in one of both vessels, then the corresponding vessel was locked up with a lid of perforated filter paper. H. nitidus individuals were counted in each area at each time. Mean differences between both areas in the ten boxes (replicates) were compared in the same way as in previous experiments.

\section{Results}

\subsection{Direct contact with earthworm excreta}

H. nitidus was significantly more abundant on half-disks impregnated with mucus and urine from $A$. giardi than on half-disks saturated with deionized water (Table 1). H. nitidus was also more attracted by mucus and urine from A. chlorotica than by water (Table 1) and the attraction was faster than for A. giardi (Fig. 2A). Preliminary experiments in the same conditions but using earthworms previously kept on moistened paper 
during 0,12 or $36 \mathrm{~h}$ instead of $60 \mathrm{~h}$ (thus the gut was incompletely voided), gave similar results (data not shown), confirming the trend of the choice exerted by animals. The control experiment indicated the absence of an uncontrolled preference within the dish (Table 1). Thus mucus and urine of both earthworm species attracted H. nitidus individuals. Observations between successive measurements showed that generally Collembola did not redistribute between half-disks when in contact with mucus and urine from earthworms. Numerical changes were only due to new individuals coming in from other places of the Petri dish.

When $H$. nitidus individuals were allowed to choose between calcic mull and casts of A. giardi or $A$. chlorotica, their density was slightly higher on casts but differences between both substrates were not significant (Table 2, Fig. 2B).

In the presence of stained half-disks, H. nitidus individuals did not show any preferences for a given area in the control experiment (Table 3). All animals survived and were distributed as in the case of undyed halfdisks (Fig. 2C, compare to Fig. 2A). Thus the methyl blue dye did not affect the distribution and the behaviour of Collembola. In experiments with water only, neither the gut contents nor ventral tubes of Collembola showed any blue coloration, indicating that in the absence of mucus they did not suck on the half-disks. When one of the two half-disks was saturated with mucus and urine from A. giardi then the corresponding number of $H$. nitidus was significantly higher on it (Table 3). The abundance of animals on mucus and urine increased up to $60 \mathrm{~min}$ and thereafter remained stable (Fig. 2C). Methyl blue did not disturb the attraction of H. nitidus by mucus and urine (compare with Fig. 2A). Forty per cent of individuals exhibited a blue coloration in their gut, indicating that Collembola sucked on methyl blue stained half-disks impregnated with mucus and urine. Two individuals (3\%) had only the end of their ventral tube blue stained.

\subsection{Odour of earthworm and earthworm excreta (casts + mucus + urine $)$}

The first odour experiment (Table 4) showed that H. nitidus was significantly more abundant in the sector above earthworm excreta than in the sector without the odour of earthworm excreta, especially from 80 min onwards (Fig. 3A). $80 \mathrm{~min}$ is probably the time needed for Collembola to explore their milieu and for the odour to reach them. The aggregation towards the side with odour of earthworm excreta increased with time up to the end of the experiment, i.e. $160 \mathrm{~min}$ (Fig. 3). The control experiment showed a little but not significant 
clustering of animals which occurred indifferently in one of both sectors (Table 4 and Fig. 3A).

Because a threshold level was not reached at the end of the 160 min experiment, a longer-lasting experiment was performed over $420 \mathrm{~min}$ (Fig. 3B). H. nitidus was significantly more abundant in the 'earthworm excreta odour' sector (Table 4) particularly from $60 \mathrm{~min}$ up to the end of the experiment (Fig. 3B). Thus, the attraction of Collembola by the odour of earthworm excreta became effective at the same time as in the shorter experiment and was stable over time, maybe reinforced by aggregation pheromones. In the control experiment the individuals tended to aggregate in one or the other of both sectors, as indicated by the high level of standard errors (Fig. 3B). Collembola were slightly more abundant in one of both sectors, but this trend was not significant.

The experiment using the device with smaller moist areas gave results different from those obtained with a wider moist area. In the control experiment with water only the mean difference between both areas was not significant and smaller than in the previous experiment and the standard error was reduced thus indicating a better balanced distribution (Table 5 and Fig. 3C). The experiment using earthworm excreta indicated that the number of H. nitidus was always higher in the area 'earthworm excreta odour' (Fig. 3C) but that this preference was not significant (Table 5). However, the preference became significant $(\mathrm{P}=0.005)$ when an outlier replicate (where an unexpected aggregation occurred in the area "no odour") was eliminated.

When earthworm excreta were replaced by earthworms, the mean abundance of Collembola was significantly higher in the area with the odour of earthworms than in the area without odour (Table 5 and Fig. 3C). Thus earthworms themselves, not defecating but rather excreting mucus and urine, produced an olfactory signal, which was attractive to $H$. nitidus. The attraction occurred more rapidly with the odour of earthworms than with that of their excreta.

\section{Discussion}

\subsection{Direct contact with earthworm excreta}

The mixture of mucus and urine excreted by the earthworms A. giardi and A. chlorotica strongly attracted $H$. nitidus individuals when direct contact was possible. Earthworm mucus is known to affect insect 
behaviour, either as an attractant (Morris and Pivnick, 1991), or as a repellent (Laakso and Setailai, 1997). The earthworm Lumbricus terrestris has been shown to excrete a cutaneous snake-attracting compound that acts after contact through the vomeronasal system of the snake (Halpern et al., 1984; Kirschenbaum et al., 1985; Wang et al., 1988). Attraction could be mediated by various nitrogenous molecules which are contained in the epidermal earthworm mucus (glycoproteins, peptides, amino acids) and in urine (ammonia, urea) which mingles with mucus (El Duweini and Ghabbour, 1971; Cortez and Bouché, 1987).

The frst two experiments indicated that $H$. nitidus was attracted more rapidly by mucus and urine of $A$. chlorotica than by that of A. giardi. This suggests that this kind of attraction varies according to the earthworm species. However the attraction could vary according to experimental conditions and physiological state of earthworms, since in the experiment with methyl blue the attraction by excreta of A. giardi was more rapid than without staining. In addition the sensitivity of Collembola to signals, like their aggregational habit, could vary whether they are feeding or moulting (Joosse and Verhoef, 1974; Bengtsson et al., 1994; Eisenbeis, 1982).

Some of the components of earthworm mucus or urine not only constituted an attractant for H. nitidus but also induced sucking of impregnated filter paper. The fact that collembolan guts did not contain methyl blue in the absence of mucus and urine (control experiment with water only) gave indirect evidence that earthworm epidermal excreta were actually absorbed by $H$. nitidus. This result means that one of the reasons for the attraction is that $H$. nitidus may feed on earthworm mucus or urine. These excreta contain a number of nitrogenrich molecules (see above) and epidermal mucus also contains easily assimilable carbohydrates (Cortez and Bouché, 1987) which may be consumed by Collembola.

Two individuals found with the apex of their ventral tube stained blue had probably tried to absorb mucus by this way, unless staining occurred during absorption of water only. Nevertheless this mode of absorption could be taken as negligible since the ventral tube is better known to allow uptake of diluted salt solutions (Eisenbeis, 1982) rather than that of high molecular weight compounds such as mucus and methyl blue. Earthworm urine could nonetheless be absorbed by this way.

A set of choice experiments, not described in this paper, has been performed in darkness on isolated individuals, thus preventing aggregation and interaction with light. Animals were repeatedly photographed under fash. A preference of H. nitidus for mucus plus urine was demonstrated with both A. chlorotica and A. giardi. 
Although these results confirmed the above demonstrated preferences, data are not shown here because unexpected preferences for a given side were observed in the control experiment with water only. The flash was probably responsible for this bias as it affected the behaviour of the animals. Nevertheless these choice experiments using methyl blue stained filter paper supported the absorption of mucus and urine by $H$. nitidus, since a blue coloration of gut contents was observed only in the presence of A. giardi and A. chlorotica excreta.

Casts of A. giardi and A. chlorotica did not significantly attract $H$. nitidus. At first sight this result is surprising since earthworm faeces concentrate a number of nutrients like N (Scheu, 1987; Parkin and Berry, 1994), Ca and P (Heine and Larink, 1993; Sharpley and Syers, 1976; Lunt and Jacobson, 1944). Moreover $H$. nitidus ingest mainly invertebrate faeces (Arpin et al., 1980; Salmon, unpublished). In our experiments, the number of individuals was always greater, although not significantly, in fresh casts than in calcic mull made of aged casts. Earthworm faeces contain intestinal mucus but most of the nitrogenous compounds within it are reabsorbed in the foregut (Martin et al., 1987; Bernier, 1998). Bouché et al. (1997) estimated that N excretion by epidermal mucus of earthworms exceeded that by faeces. Thus our results reinforce the hypothesis that $H$. nitidus may be attracted by easily available nitrogen-rich compounds such as amino-acids, proteins, urea and ammonia, which can be used by hexapods in protein synthesis (Martin, 1979).

\subsection{Odour of earthworm and earthworm excreta}

Our experiments showed that $H$. nitidus was attracted by the odour of $A$. giardi and to a less extent by the odour of its excreta (mucus, urine and faeces) although this attraction did not occur systematically. Ammonia and amino acids are volatile attractants for a fruit fly (Morton and Bateman, 1981; Bateman and Morton, 1981). Thus, some nitrogenous compounds present in earthworm excreta (see above) might be volatile and attract Collembola at a distance.

The attraction was more efficient when $H$. nitidus was allowed to contact mucus and urine (attraction always significant) than when it perceived only the odour of excreta. In addition it was necessary to increase the number of replicates and individuals in order to detect the effect of odour. The attraction after direct contact is the common case in the interactions between earthworms and other animals (see above mentioned references). In our odour experiments this attraction occurred at $1 \mathrm{~cm}$ distance. This is a short distance compared to field 
conditions, except if the olfactory signal can be transported by an air stream, like for instance in an earthworm burrow. Moreover the olfactory attraction of $H$. nitidus by A. giardi did not occur systematically in our experiments and some (but not significant) aggregation arose in one of both sectors even in the absence of earthworm odour. Thus in field conditions the attraction by the odour of earthworm excreta probably interacts with one or several other factors.

In another experiment (not presented here), Collembola exhibited no preference at all for the odour of earthworm excreta. We attributed this negative result to the fact that excreta were not moist enough (with regard to other experimental runs). Variations from a replicate to another in the same experiment and from an experiment to another could be due to the fact that the volatility of the chemicals involved in the attraction is weak as in the case for amino acids (Morton and Bateman, 1981). Another explanation, compatible with the former, is that light may interact with the odour of earthworm excreta. Although experiments were carried out in darkness, test-boxes were submitted to ambient light for a short time during counting. In fact, light has a strong effect on the distribution of $H$. nitidus (Salmon and Ponge, 1998). The effect of light may persist in darkness, probably following the deposition of aggregation pheromones (Krool and Bauer, 1987). Interactions between light and odour of earthworms or earthworm excreta could partially explain the absence of attraction by odour in some replicates as well as the aggregation observed in the control experiment over $430 \mathrm{~min}$. Our experiments also revealed that clustering interacted with the attraction to earthworm odour. H. nitidus produces an aggregation pheromone which induces a decrease in its locomotory activity (Verhoef et al., 1977; Verhoef, 1984; Krool and Bauer, 1987). This effect depends on environmental factors like water and food availability, physiological state and population density (Usher and Hider, 1975; Verhoef and Nagelkerke, 1977; Leonard and Bradbury, 1984; Bengtsson et al., 1994). When individuals find favourable conditions, (e.g. in our moist experimental environment), together with the odour of earthworm excreta and darkness, they cluster and remain motionless. This probably lasts until they need to seek food (Verhoef and Nagelkerke, 1977). As in the present study, the pH preferenda of Folsomia candida (Van Straalen and Verhoef, 1997) could not be determined accurately because of interaction with a similar aggregative process.

\section{Conclusion}


We proved that the mixture of earthworm mucus and urine is a strong attractant for $H$. nitidus while the impact of the odour of earthworm excreta on the distribution of this species is not very pronounced, and the contact with earthworm faeces not efficient. We showed as well that $H$. nitidus absorbs earthworm mucus. The attraction to earthworm mucus, which lines burrow walls (Kretzschmar, 1987), could thus explain at least partly the field distribution of $\mathrm{H}$. nitidus according to a trophic interaction. This conclusion corroborates the results of field studies from which H. nitidus had been found only in mull at $\mathrm{pH}>5$ (Ponge, 1993; Salmon and Ponge, 1999) that is a humus form characterized by a high number and diversity of earthworms (Ponge et al., 1997). In mull humus at $\mathrm{pH}<5$ this collembolan species is absent (Ponge, 1993). A choice experiment designed to assess the attraction of Collembola by mucus and urine from earthworms living at $\mathrm{pH}<5$ will enable a better understanding of the distribution of $H$. nitidus in the field.

\section{Acknowledgements}

We wish to acknowledge Marc Théry for lending us light sensors and data recorders. We are grateful to Marielle Peroz and particularly Ceril Techer from the Laboratory, who assisted in sampling earthworms.

\section{References}

Arbea, J.I., Jordana, R., 1988. Nota sobre la presencia masiva de Onychiurus folsomi Schaeffer (Collembola, Onychiuridae) en lechos de Eisenia andrei (Oligochaeta, Lumbricidae). Boletin de Sanidad Vegetal, Plagas 14, 535-540.

Arpin, P., Kilbertus, G., Ponge, J.F., Vannier, G., 1980. Importance de la microflore et de la microfaune en milieu forestier. In: Pesson, P. (Ed.). Actualités d'écologie Forestière. Gauthier-Villars, Paris, pp. 87150.

Bateman, M.A., Morton, T.C., 1981. The importance of ammonia in proteinaceous attractants for fruit flies (family: Tephridae). Australian Journal of Agricultural Research 32, 883-903.

Bauer, T., Christian, E., 1987. Habitat dependent differences in the flight behavior of Collembola. Pedobiologia 
$30,233-239$.

Bayoumi, B.M., 1978. Signifcance of the microhabitat on the distribution of oribatid mites in a hornbeam-oak mixed forest. Opuscula Zoologica Budapest 15, 51-59.

Bengtsson, G., Erlandsson, A., Rundgren, S., 1988. Fungal odour attracts soil Collembola. Soil Biology \& Biochemistry 20, 25-30.

Bengtsson, G., Hedlund, K., Rundgren, S., 1994. Food-and density-dependent dispersal: evidence from a soil collembolan. Journal of Animal Ecology 63, 513-520.

Bernier, N., 1998. Earthworm feeding activity and development of the humus profle. Biology \& Fertility of Soils 26, 215-223.

Bouché, M.B., 1972. Lombriciens de France. Ecologie et systematique. I.N.R.A, Paris.

Bouché, M.B., Aladdan, F., Cortez, J., Hammed, R., Heidet, J.C., Ferriere, G., Mazaud, D., Samih, M., 1997. Role of earthworms in the N cycle: A falsifiable assessment. Soil Biology \& Biochemistry 29, 375380.

Brown, G.G., 1995. How do earthworms affect microfloral and faunal community diversity? Plant \& Soil 170, 209-231.

Cortez, J., Bouché, M., 1987. Composition chimique du mucus cutané de Allolobophora chaetophora chaetophora (Oligochaeta: Lumbricidae). Comptes-Rendus de l'Académie des Sciences de Paris, Série III 305, 207-210.

Devliegher, W., Verstraete, W., 1997. Microorganisms and soil physic-chemical conditions in the drilosphere of Lumbricus terrestris. Soil Biology \& Biochemistry 29, 1721-1729.

Dubash, P.J., Ganti, S.S., 1964. Earthworms and amino-acids in soil. Current Science 7, 219-220.

Eisenbeis, G., 1982. Physiological absorption of liquid water by Collembola: absorption by the ventral tube at different salinities. Journal of Insect Physiology 28, 11-20.

El Duweini, A.K., Ghabbour, I., 1971. Nitrogen contribution by live earthworms to the soil. IVth Colloquium 
Pedobiologiae, 1970, September, Dijon, France INRA, Paris, pp. 495-501.

Greenslade, P., Fletcher, K.E., 1986. Collembola from earthworm rearing beds at Rothamsted including three new records for Britain. Entomologist's Monthly Magazine 122, 143-144.

Halpern, N., Schulman, N., Scribani, L., Kirschenbaum, D.M., 1984. Characterization of vomeronasallymediated response-eliciting components of earthworm wash. II. Pharmacology, Biochemistry \& Behavior 21, 655-662.

Hamilton, W.E., Sillman, D.Y., 1989. Infuence of earthworm middens on the distribution of soil microarthropods. Biology \& Fertility of Soils 8, 279-284.

Hedlund, K., Bengtsson, G., Rundgren, S., 1995. Fungal odour discrimination in two sympatric species of fungivorous collembolans. Functional Ecology 9, 869-875.

Heine, O., Larink, O., 1993. Food and cast analyses as a parameter of turn-over of materials by earthworms (Lumbricus terrestris L.). Pedobiologia 37, 245-256.

Huber, I., 1979. Prey attraction and immobilization by allelomone from nymphs of Womersia strandtmanni (Acarina: Trombiculidae). Acarologia 20, 112-115.

Jeanson, C., 1972. Etude microscopique de depôts de fer, de manganèse et de calcium dans un sol expérimental, leur association avec des microorganismes. Revue d'Ecologie et de Biologie du Sol 9, 479-489.

Joosse, E.N.G., Verhoef, H.A., 1974. On the aggregational habits of surface-dwelling Collembola. Pedobiologia $14,245-249$.

Kaneko, N., McLean, M.A., Parkinson, D., 1995. Grazing preference of Onychiurus subtenuis (Collembola) and Opiella nova (Oribatei) for fungal species inoculated on pine needles. Pedobiologia 39, 538-546.

Kirschenbaum, D.M., Schulman, N., Yao, P., Halpern, N., 1985. Chemoattractant for the garter snake: Characterization of vomeronasally-mediated response-eliciting components of earthworm wash. III. Comparative Biochemistry \& Physiology, 82B, 447-453.

Kozlovskaja, L.S., 1969. Der Einflu $\beta$ der Exkremente von Regenwuirmen auf die Aktivierung der mikrobiellen 
Prozesse in Torfboiden. Pedobiologia 9, 158-164.

Kretzschmar, A., 1987. Caractérisation microscopique de l'activité des lombriciens endogés. In: Fedoroff, N., Bresson, L.M., Courty, M.A. (Eds.). Micromorphologie des sols. Soil Micromorphology. AFES, Paris, pp. 325-330.

Krool, S., Bauer, T., 1987. Reproduction, development and pheromone secretion in Heteromurus nitidus Templeton, 1835 (Collembola, Entomobryidae). Revue d'Ecologie et de Biologie du Sol 24, 187-195.

Laakso, J., Setailai, H., 1997. Nest mounds of red wood ants (Formica aquilonia): hot spots for litter-dwelling earthworms. Oecologia 111, 565-569.

Leonard, M.A., Bradbury, P.C., 1984. Aggregative behaviour in Folsomia candida (Collembola: Isotomidae) with respect to previous conditioning. Pedobiologia 26, 369-372.

Loranger, G., Ponge, J.F., Blanchart, E., Lavelle, P., 1998. Impact of earthworms on the diversity of microarthropods in a vertisol (Martinique). Biology \& Fertility of Soils 27, 21-26.

Lunt, H.A., Jacobson, H.G.M., 1944. The chemical composition of earthworm casts. Soil Science 58, 367-375.

Marinissen, J.C.Y., Bok, J., 1988. Earthworm-amended soil structure: its infuence on Collembola populations in grassland. Pedobiologia 32, 243-252.

Martin, A., Cortez, J., Barois, I., Lavelle, P., 1987. Les mucus intestinaux de Ver de terre moteur de leurs interactions avec la microflore. Revue d'Ecologie et de Biologie du Sol 24, 549-558.

Martin, M.M., 1979. Biochemical implications of insect mycophagy. Biological Review 54, 1-21.

Morris, D.E., Pivnick, K.A., 1991. Earthworm mucus stimulates oviposition in a predatory fly (Diptera: Anthomyiidae). Journal of Chemical Ecology 17, 2045-2052.

Morton, T.C., Bateman, M.A., 1981. Chemical studies on proteinaceous attractants for fruit flies, including the identification of volatile constituents. Australian Journal of Agricultural Research 32, 905-916.

Parkin, T.B., Berry, E.C., 1994. Nitrogen transformations associated with earthworm casts. Soil Biology \& Biochemistry 26, 1233-1238. 
Piearce, T.G., 1972. Acid intolerant and ubiquitous Lumbricidae in selected habitats in North Wales. Journal of Animal Ecology 41, 397-410.

Ponge, J.F., 1993. Biocenoses of Collembola in atlantic temperate grass-woodland ecosystems. Pedobiologia $37,223-244$.

Ponge, J.F., Arpin, P., Sondag, F., Delecour, F., 1997. Soil fauna and site assessment in beech stands of the Belgian Ardennes. Canadian Journal of Forest Research 27, 2053-2064.

Robinson, C.H., Ineson, P., Piearce, T.G., Rowland, A.P., 1992. Nitrogen mobilization by earthworms in limed peat soils under Picea sitchensis. Journal of Applied Ecology 29, 226-237.

Sadaka-Laulan, N., Ponge, J.-F., Roquebert, M.-F., Bury, E., Boumezzough, A., 1999. Feeding preferences of the collembolan Onychiurus sinensis for fungi colonizing holm oak litter (Quercus rotundifolia Lam.). European Journal of Soil Biology 34, 179-188.

Saetre, P., 1998. Decomposition, microbial community structure, and earthworm effects along a birch-spruce soil gradient. Ecology 79, 834-846.

Salmon, S., Ponge, J.-F., 1999. Distribution of Heteromurus nitidus (Hexapoda, Collembola) according to soil acidity: interactions with earthworms and predator pressure. Soil Biology \& Biochemistry 31, 11611170.

Salmon, S., Ponge, J.-F., 1998. Effect of light on a soil-dwelling springtail. European Journal of Soil Biology 34, 199-201.

Satchell, J.E., 1967. Lumbricidae. In: Burges, A., Raw, F. (Eds.). Soil Biology. Academic Press, London, pp. 259-322.

Scheu, S., 1987. Microbial activity and nutrient dynamics in earthworm casts (Lumbricidae). Biology \& Fertility of Soils 5, 230-234.

Sharpley, A.N., Syers, J.K., 1976. Potential role of earthworms casts for the phosphorus enrichment of run-off waters. Soil Biology \& Biochemistry 8, 341-346. 
Shaw, P.J.A., 1988. A consistent hierarchy in the fungal feeding preferences of the Collembola Onychiurus armatus. Pedobiologia 31, 179-187.

Sokal, R.R., Rohlf, F.J., 1995. Biometry. 3rd ed. W.H. Freeman and Co, New York.

Subler, S., Kirsch, A.S., 1998. Spring dynamics of soil carbon, nitrogen, and microbial activity in earthworm middens in a no-till cornfeld. Biology \& Fertility of Soils 26, 243-249.

Thimm, T., Larink, O., 1995. Grazing preferences of some Collembola for endomycorrhizal fungi. Biology \& Fertility of Soils 19, 266-268.

Usher, M.B., Hider, M., 1975. Studies on populations of Folsomia candida (Insecta: Collembola): causes of aggregations. Pedobiologia 15, 276-283.

Van Straalen, N.M., Verhoef, H.A., 1997. The development of a bioindicator system for soil acidity based on arthropod pH preferences. Journal of Applied Ecology 34, 217-232.

Verhoef, H.A., 1984. Releaser and primer pheromones in Collembola. Journal of Insect Physiology 30, 665670.

Verhoef, H.A., Nagelkerke, C.J., 1977. Formation and ecological significance of aggregations in Collembola. Oecologia 31, 215-226.

Verhoef, H.A., Nagelkerke, C.J., Joosse, E.N.G., 1977. Aggregation pheromones in Collembola. Journal of Insect Physiology 23, 1009-1013.

Wang, D., Chen, P., Jiang, X.C., Halpern, M., 1988. Isolation from earthworms of a proteinaceous chemoattractant to garter snakes. 215-226. Archives of Biochemistry \& Biophysics 267, 459-466.

Wickenbrock, L., Heisler, C., 1997. Infuence of earthworm activity on the abundance of collembola in soil. Soil Biology \& Biochemistry 29, 517-521. 


\section{Legends of figures}

Figure 1. Design of test-boxes used in odour experiments with one moistened area of filter paper as bottom substrate for Collembola.

Figure 2. Differences in the number of Heteromurus nitidus (means of six replicates \pm standard errors) between two half-disks of filter paper ('earthworm excreta' versus 'reference substrate') in an experiment involving a direct contact over 140 min. (A) Experiment with mucus and urine versus water. (B) Experiment with fresh casts versus calcic mull. (C) Experiment with mucus and urine versus water in half-disks previously stained with methyl blue dye.

Figure 3. Differences in the number of Heteromurus nitidus (means of ten replicates \pm standard errors) between two sectors ('earthworm excreta odour' or 'earthworm odour' versus 'no odour') in odour experiments. (A) Experiments over 160 and 130 min with two sectors in a moist area of filter paper. (B) Experiment over 420 min with two sectors in a moist area of filter paper. (C) Experiment over 330 min with two distinct moist areas of filter paper. 
Table 1 Numbers of H. nitidus on each half-disk in three choice experiments involving a direct contact over 140 $\min$ (means of 14 times and six replicates). NS $=$ not significant at 0.05 level; $* *, * * *=$ significant at the 0.01 and levels, respectively

\begin{tabular}{lll}
\hline Content of half-discs & $\begin{array}{l}\text { Number of H. nitidus } \\
\text { (mean } \pm \text { SEM) }\end{array}$ & $\begin{array}{l}\text { Results of paired t test } \\
\text { (probability) }\end{array}$ \\
\hline Mucus and urine of A. giardi & $6.04 \pm 0.34$ & $0.0001^{* * *}$ \\
Water & $1.32 \pm 0.18$ & \\
& & \\
Mucus and urine of A. chlorotica & $8.23 \pm 0.73$ & $0.0063 * *$ \\
Water & $1.58 \pm 0.74$ & \\
Water (disk E1) & $3.95 \pm 0.53$ & $0.7889 \mathrm{NS}$ \\
Water (disk E2) & $3.69 \pm 0.40$ & \\
\hline
\end{tabular}


Table 2 Numbers of $H$. nitidus on each half-disk in two choice experiments involving a direct contact over 140 $\min$ (means of 14 times and six replicates). NS = not significant at 0.05 level

\begin{tabular}{lll}
\hline Content of half-discs & $\begin{array}{l}\text { Number of } H . \text { nitidus } \\
\text { (mean } \pm \text { SEM) }\end{array}$ & $\begin{array}{l}\text { Results of paired t test } \\
\text { (probability }\end{array}$ \\
\hline Fresh casts of $A$. giardi & $5.61 \pm 0.92$ & 0.2049 NS \\
Calcic mull & $2.99 \pm 0.88$ & \\
Fresh casts of A. chlorotica & $5.87 \pm 1.01$ & $0.2661 \mathrm{NS}$ \\
Calcic mull & $3.49 \pm 0.90$ & \\
\hline
\end{tabular}


Table 3 Numbers of H. nitidus on each half-disk in two choice experiments involving a direct contact over 140 $\min$ (means of 14 times and six replicates). NS $=$ not significant at 0.05 level; $*=$ significant at 0.05 level

\begin{tabular}{lll}
\hline Content of half-discs & $\begin{array}{l}\text { Number of H.nitidus } \\
\text { (mean } \pm \text { SEM) }\end{array}$ & $\begin{array}{l}\text { Results of paired t test } \\
\text { (probability) }\end{array}$ \\
\hline Methyl blue + water (E1) & $2.92 \pm 0.44$ & $0.5606 \mathrm{NS}$ \\
Methyl blue + water (E2) & $3.39 \pm 0.65$ & \\
& & $0.0134^{*}$ \\
Methyl blue + mucus and urine of A. giardi & $7.51 \pm 1.08$ & \\
Methyl blue + water & $1.08 \pm 0.66$ & \\
\hline
\end{tabular}


Table 4 Numbers of $H$. nitidus in each sector of a moist area of filter paper, in the first set of four odour experiments (means of respectively 16,13 or 14 times and ten replicates). NS = not significant at 0.05 level; **, *** = significant at the 0.01 and 0.001 levels, respectively

\begin{tabular}{|c|c|c|c|}
\hline Experiments & $\begin{array}{l}\text { Odour occurrence in } \\
\text { sectors }\end{array}$ & $\begin{array}{l}\text { Number of } H \text {. nitidus } \\
\text { (mean } \pm \text { SEM) }\end{array}$ & $\begin{array}{l}\text { Results of paired } \\
t \text { test (probability) }\end{array}$ \\
\hline \multirow[t]{2}{*}{ Odour of earthworm excreta over $160 \mathrm{~min}$} & $\begin{array}{l}\text { Odour of } A . \text { giardi } \\
\text { excreta }\end{array}$ & $8.44 \pm 0.94$ & \multirow[t]{2}{*}{$0.0078 * *$} \\
\hline & No odour (water) & $3.54 \pm 0.92$ & \\
\hline \multirow[t]{2}{*}{ Control over $130 \mathrm{~min}$} & No odour (water) & $6.12 \pm 0.97$ & \multirow[t]{2}{*}{$0.8703 \mathrm{NS}$} \\
\hline & No odour (water) & $5.87 \pm 0.98$ & \\
\hline \multirow[t]{2}{*}{ Odour of earthworm excreta over $420 \mathrm{~min}$} & $\begin{array}{l}\text { Odour of } A \text {. giardi } \\
\text { excreta }\end{array}$ & $9.86 \pm 0.66$ & \multirow[t]{2}{*}{$0.0000 * * *$} \\
\hline & No odour (water) & $2.12 \pm 0.67$ & \\
\hline \multirow[t]{2}{*}{ Control over 420 min } & No odour (water) & $7.64 \pm 1.58$ & \multirow[t]{2}{*}{$0.2139 \mathrm{NS}$} \\
\hline & No odour (water) & $4.37 \pm 1.57$ & \\
\hline
\end{tabular}


Table 5 Numbers of H. nitidus in each of two distinct moist areas of filter paper, in three odour experiments over $330 \mathrm{~min}$ (means of 11 times and ten replicates). NS = not significant at 0.05 level; ** = significant at 0.01 level

\begin{tabular}{llll}
\hline Experiments & $\begin{array}{l}\text { Odour occurrence in } \\
\text { sectors }\end{array}$ & $\begin{array}{l}\text { Number of } H . \text { nitidus } \\
\text { (mean } \pm \text { SEM) }\end{array}$ & $\begin{array}{l}\text { Results of paired t } \\
\text { test (probability) }\end{array}$ \\
\hline Control over 330 min & $\begin{array}{l}\text { No odour (water) } \\
\text { No odour (water) }\end{array}$ & $\begin{array}{l}5.35 \pm 0.76 \\
4.93 \pm 0.54\end{array}$ & 0.6613 NS \\
Odour of earthworm excreta over 330 min & $\begin{array}{l}\text { Odour of } A \text {. giardi excreta } \\
\text { No odour (water) }\end{array}$ & $\begin{array}{l}7.31 \pm 1.14 \\
4.27 \pm 1.18\end{array}$ & 0.1252 NS \\
Odour of earthworm over 330 min & $\begin{array}{l}\text { Odour of } A \text {. giardi } \\
\text { No odour (water) }\end{array}$ & $\begin{array}{l}8.03 \pm 0.70 \\
3.38 \pm 0.70\end{array}$ \\
\hline
\end{tabular}




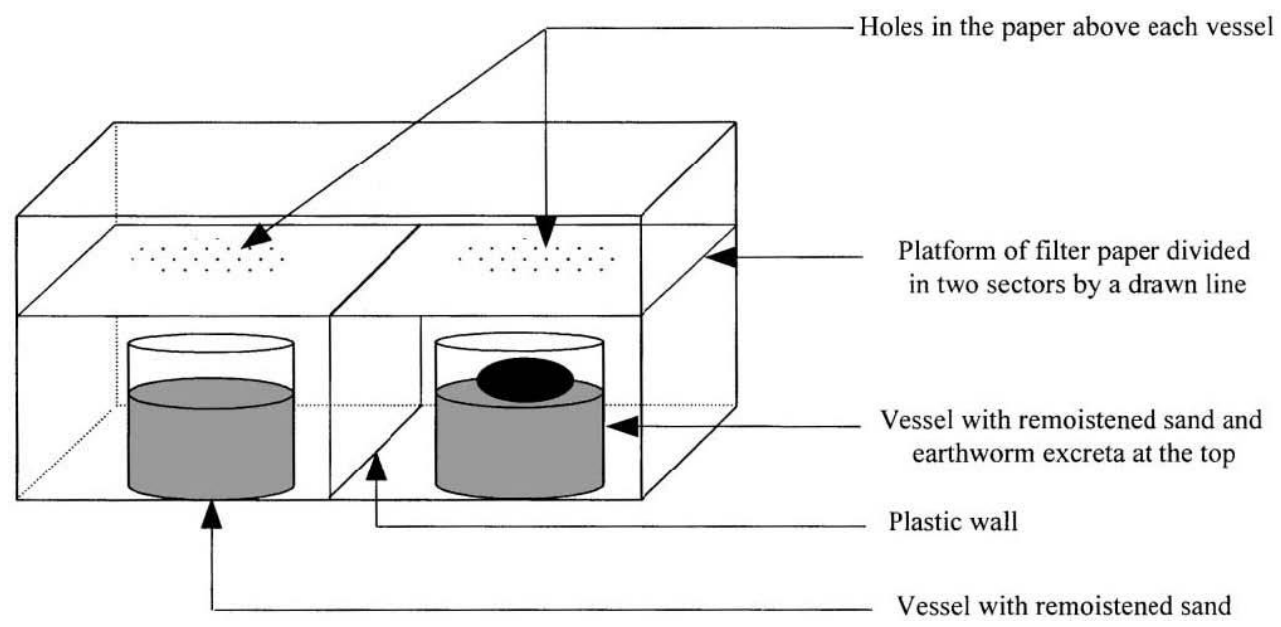

Fig. 1 
A. Direct contact with mucus and urine/water

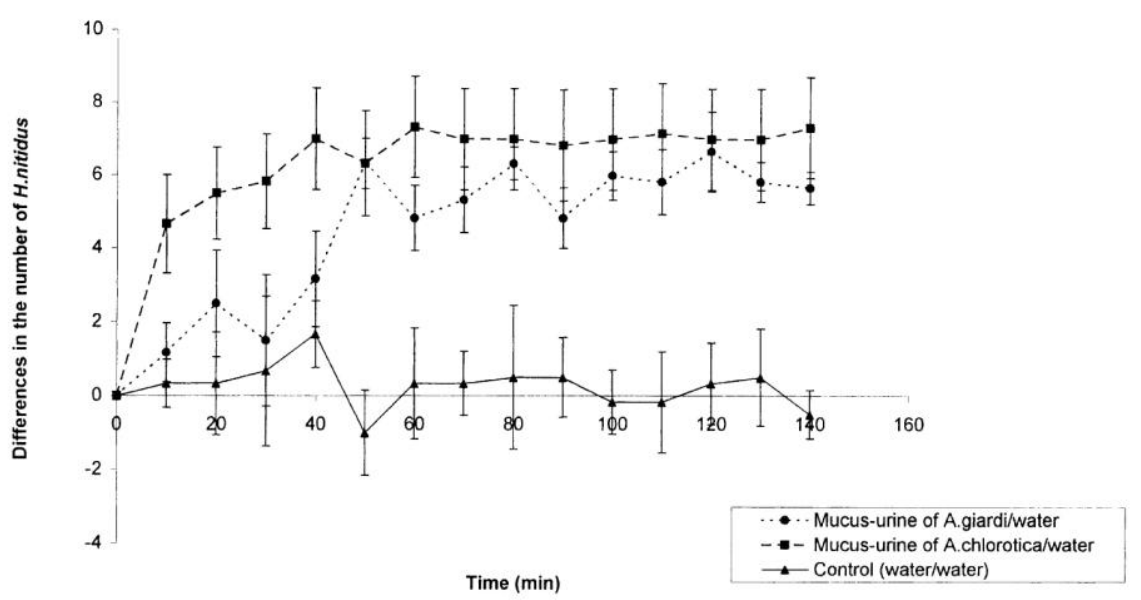

B. Direct contact with fresh casts/calcic mull
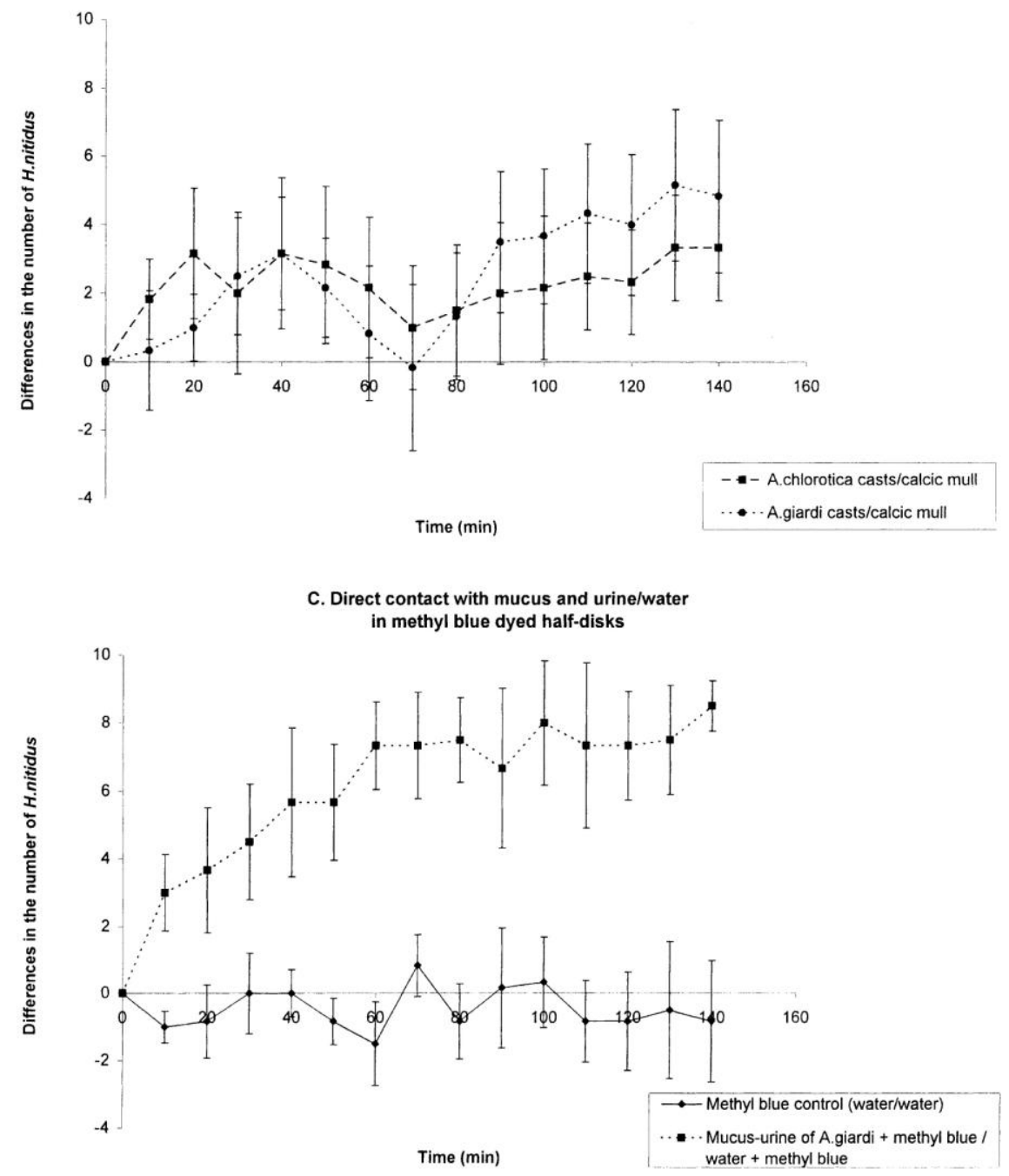

Fig. 2 
A. Odour experiment over $160 \mathrm{~min}$ and $130 \mathrm{~min}$

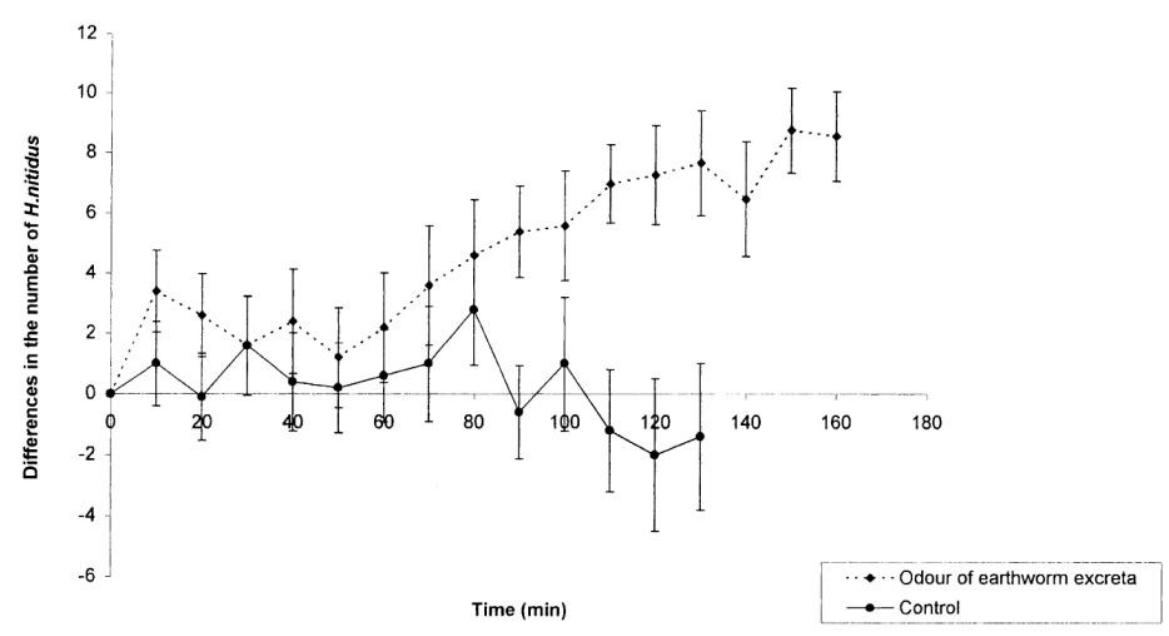

B. Odour experiment over $420 \mathrm{~min}$

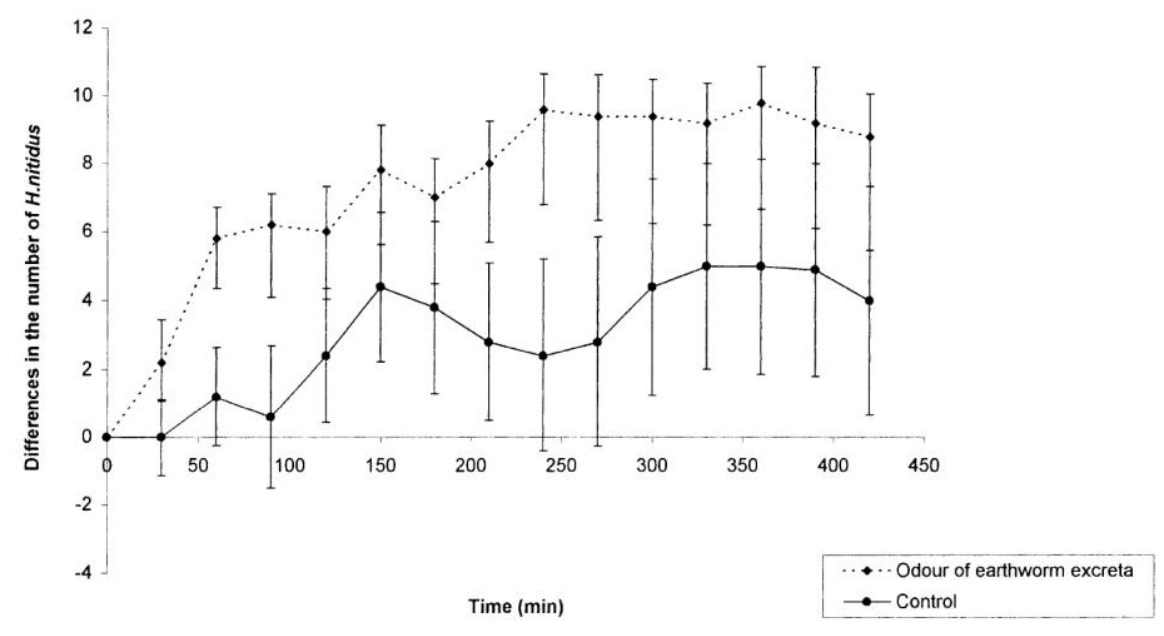

C. Odour experiment with two moist areas

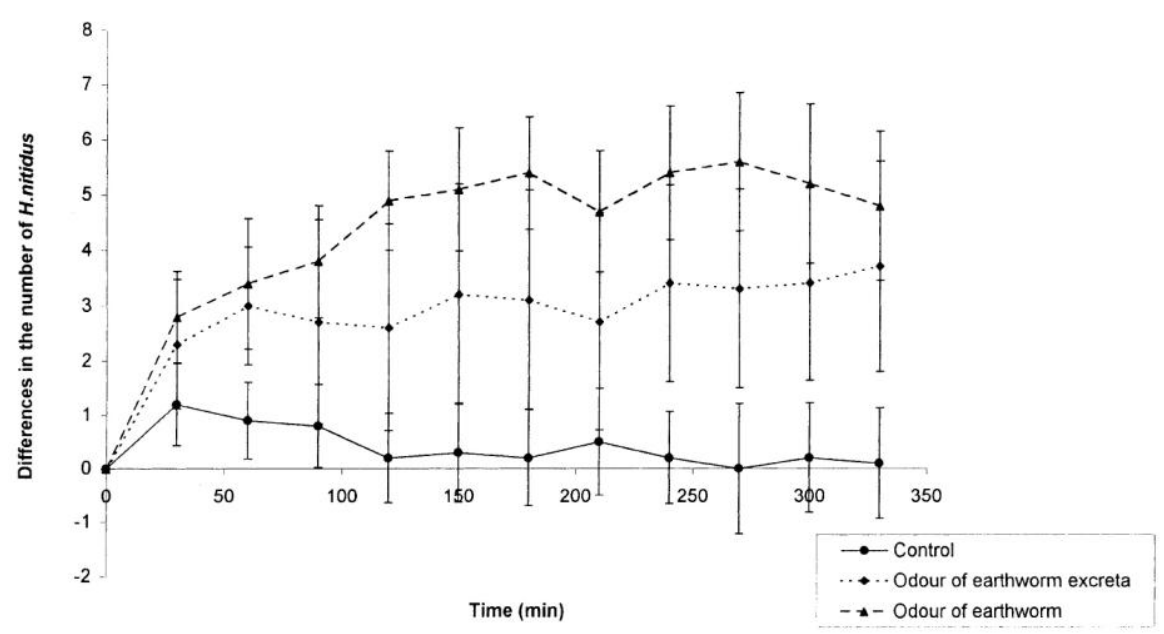

Fig. 3 